\title{
The Effectiveness of Mindfulness Training on Self-Control among University Students in Yazd
}

\author{
Fariba Olia \\ Department of Psychology, Kerman Branch, Islamic Azad University, Kerman, Iran \\ E-mail:faribaolia@yahoo.com
}

\section{Mohsen Saeedmanesh}

Corresponding Author: Assistant Professor, Department of Psychology, Yazd University of Science and Art, Yazd, Iran E-mail:m.saeidmanesh@yahoo.com

\section{Doi:10.5901/mjss.2016.v7n3s3p360}

\section{Abstract}

\begin{abstract}
This study aimed to determine the effectiveness of mindfulness training on improving self-control in female students living in Yazd dormitory in 2015. In addition to a control group, a quasi-experimental as well as pretest-posttest design was applied for this study. The study population includes all female students of Islamic Azad University of Yazd living in the dormitory in the academic. Thirty-eight subjects were selected by convenience sampling and were randomly placed into two groups: the control group and experimental groups. The Brief Self-Control Scale of Tangney and et.al (2004) was used to collect data. The experimental group participated in an 8-week mindfulness training course, one two-hour session a week and control group did not receive any intervention. The data were analyzed using analysis of covariance and independent t-test. The result of analysis of covariance showed that mindfulness training significantly increased self-control and other aspects of it in the female students living in dormitories.
\end{abstract}

Keywords: mindfulness, self-control, Female Dormitory Resident Students

\section{Introduction}

The transition from college is challenging and difficult for most students. Factors such as age-related susceptibility, being away from family, dormitory problems and dealing directly with the opposite sex lead to hedonistic, impulsive, competitive and pretentious behaviors. In this respect, self-control is considered as one of the important issues which should be enhanced in such circumstances (Mahram \& Saketi, 2008). Individuals with high self-control are hardworking, trustable and organized (Tangney et al, 2004). Individuals with high self-control have better adjustment, better interpersonal relations and better performance in academic and educational assignments. People with low skills in this area are not predictable in terms of mood and behavior; their behavior may be defined as impulsive and immature (Gottfredson \& Hirschi, 1990). Those with low self-control always feel a sense of hopelessness, depression and apathy (Safari Dehkharqani, 2008). The concept of self-control was first introduced by Schneider (1974), which means to what extent a person is flexible or stable in his/her position. Skinner believes that self-control is an acquisitive personality trait that is learned by individuals over time. In his approach to behavior, Skinner believes the whole behavior can be controlled by its consequence that is what follows the behavior. In this regard, the mindfulness-based intervention is regarded as one of the third-generation or third wave of cognitive - behavioral therapy. Mindfulness is a form of meditation that is rooted in oriental teachings and rituals (Ost, 2008). In mindfulness, one is aware of his/her mental approach every moment; after becoming aware of the two mind methods, namely doing and being, the individual learns to move the mind from one way to the other. This requires the training of specific behavioral, cognitive and metacognitive strategies to centralize the attention (Segal et al, 2003). On the other hand, with an emphasis on modifying the behavior, gaining communication skills and learning about the opposite sex, values, attitudes and appropriate decisions, group counseling can provide the growth opportunity, change destructive behaviors and provide appropriate treatment (Gibson \& Michelle, 1994). In the present study, thus, researchers sought to address the following question: Does mindfulness training increase the selfcontrol rate of university students living in dorms? 


\section{Research Method}

In addition to a control group, a quasi-experimental as well as pretest-posttest design was applied for this study. The study population includes all female students of Islamic Azad University of Yazd living in the dormitory, which were estimated to be 644 . According to Kaplan and Sadock, 12-15 samples are required for each group. Therefore, in the present study, 38 subjects were selected by convenience sampling and were randomly placed into two groups with equal numbers: 19 subjects in the control group and 19 subjects in the experimental groups. Tangney's (2004) self-control questionnaire was also used as the pretest. The experimental group participated in an 8-week mindfulness training course, one two-hour session a week. Using the mentioned questionnaire, a post-test was distributed for the two groups.

\subsection{Instruments}

Using Tangney's (2004) self-control questionnaire, a pre-test and a post-test were used to collect the required data.

Tangney's (2004) self-control questionnaire

A shortened version of Tangney et al.'s (2004) questionnaire, consisting of 13 items, was used to measure the selfcontrol tendency. Like the complete 36-item questionnaire, this questionnaire has also the total score which includes reverse scores. De Ridder et al. (2011) considered two small scales for this version. In their study, they showed that when compared to the total score, the two small scales are better predictors of both desirable and undesirable behavior (De Ridder et al, 2011). Tangney's (2004) self-control questionnaire examines self-control in two areas: inhibitory (restraint) and initiatory (impulsivity) self-control.

Compared to inhibitory small scale, the initial self-control small scale is a better predicator of proper behaviors. In addition, inhibitory self-control predicts the prevention of unpleasant behavior. The desired test's consistency for estimating the internal consistency was confirmed. The alpha value for the 36 -item self-control scale was 0.89 in the two samples of Tangney's (2004). (The alpha value was 0.83 and 0.85 for the two samples, respectively.) Thus, the questionnaires enjoyed good internal consistency. In order to estimate the internal consistency, Cronbach's alpha was used. The total reliability coefficient was 0.80 . This coefficient was 0.74 and 0.68 for emotional stability, respectively (Sarafraz et al, 2012).

\section{Results}

Table 1. The mean and standard deviation of the age in the control and experimental group

\begin{tabular}{|l|c|c|c|c|}
\hline \multirow{3}{*}{ Variable } & \multicolumn{4}{|c|}{ Group } \\
\cline { 2 - 5 } & \multicolumn{2}{|c|}{ Control } & \multicolumn{2}{c|}{ Experimental } \\
\cline { 2 - 5 } & Mean & SD & Mean & SD \\
\hline Age & 25.37 & 3.90 & 23.16 & 2.67 \\
\hline
\end{tabular}

The above table shows that the average age was 25.37 for in the control group and 23.16 for the experimental group.

Table 2. Mean and standard deviation of the study variables in the pre-test and post-test for control and experimental groups

\begin{tabular}{|l|c|c|c|c|c|}
\hline \multirow{2}{*}{ Variable } & \multirow{2}{*}{ Phase } & \multicolumn{4}{|c|}{ Group } \\
\cline { 3 - 6 } & & \multicolumn{2}{|c|}{ Control } & \multicolumn{2}{c|}{ Experimental } \\
\cline { 3 - 6 } & & Mean & SD & Mean & SD \\
\hline \multirow{2}{*}{ Self-control } & Pre-test & 43.31 & 5.67 & 41.63 & 5.64 \\
\cline { 2 - 6 } & Post-test & 42.95 & 5.42 & 48.26 & 5.08 \\
\hline
\end{tabular}

Table 3. Independent t-test to examine the group membership differences in self-control in pretest

\begin{tabular}{|l|c|c|c|c|c|c|}
\hline Variable & Group & Mean & SD & df & T & Sig. \\
\hline \multirow{2}{*}{ Self-control } & Experimental & 41.63 & 5.64 & \multirow{2}{*}{36} & \multirow{2}{*}{0.92} & \multirow{2}{*}{0.36} \\
\cline { 2 - 4 } & Control & 43.31 & 5.67 & & \\
\hline
\end{tabular}


The above table shows that no significant difference exists in the effect of the experimental and control groups in the pretest $(P>0.05)$. Thus, it can be said that the two groups are the same in self-test variable.

Table 4. Levin test to test the hypothesis of homogeneity of variance in both the experimental and control groups in the self-control variable

\begin{tabular}{|c|c|c|c|c|c|}
\hline Variable & Phase & $\mathrm{df}(1)$ & $\mathrm{df}(2)$ & Levin test & Sig. \\
\hline Self-control & Post-test & 1 & 38 & 4.45 & 0.06 \\
\hline
\end{tabular}

The above table shows that no significant difference exists between the experimental and control group in the pre-test $(P>0.05)$. Therefore, it can be said that the two groups are homogenous in the self-test variable.

Table 5. Results of covariance analysis on the impact of group membership on self-test in the pre-test

\begin{tabular}{|l|l|c|c|c|c|c|c|}
\hline Variables & Phase & Change source & Total squares & df & Mean of squares & F coefficient & Sig. \\
\hline \multirow{3}{*}{ Self-control } & \multirow{3}{*}{ Post-test } & Pre-test & 632.89 & 1 & 632.89 & 20.10 & 0.001 \\
\cline { 3 - 8 } & & Groups & 363.96 & 1 & 363.96 & 20.16 & 0.001 \\
\cline { 2 - 8 } & & Error & 631.74 & 35 & 18.05 & - & - \\
\hline
\end{tabular}

The results of the table above shows that mindfulness training increases self-control in the post-test phase $(P \leq 0.01, F(1$, $35)=20.16)$. Thus, it can be concluded that "mindfulness training is effective in increasing self-control in the female students living in dormitory."

\section{Discussion and Conclusion}

This research aims to examine mindfulness training on self-control increase in female students living in Yazd dormitory. The results showed that mindfulness training was effective in increasing self-control at post-test. These findings are consistent with those of Eyles et al. (2015), Yusainy et al. (2015), Yusainy \& Lawrence (2015), Wittmann et al. (2014), Bowlin \& Baer (2012), Friese et al. (2012) and Pour Shahsavari (2011). In their study, Eyles et al (2015) found that the treatment of mindfulness to reduce stress can help enhance self-regulation anxiety, depression and life quality in women with metastatic breast cancer. Bowlin and Baer (2012) examined over 280 university students and concluded that a positive relationship exists between mindfulness and self-control. They also found that mindfulness is an important modulator of self-control and psychological symptoms and that self-control and self-control is an important predictor of mental health. In addition, they stated that mindfulness and self-control were significantly different from mental health. The current study is not consistent in one part with the findings of Ahmadi (2009). He suggested that problem solving training was not significantly effective in increasing self-control, positive emotion and purposefulness (Ahmadi, 2009). To explain this difference, it can be noted that mindfulness is an important infrastructure for solving the problem and having self-control since it is used to develop individual skills such as problem-solving. In general, it can be said that those who enjoy the mindfulness have some capabilities such as maintaining awareness voluntarily and based on some issues such as physical sensations in the body (e.g. breathing in and out ) from one moment to the other. These programs include some elements of cognitive therapy and would result in decentralization. For example, they include statements such as "thoughts are not reality" and "I am not my thoughts." This approach is used for decentralization as well as for emotional and physical senses. The cognitive therapy of mindfulness is designed to reduce the recurrence of depression, so that during which individuals learn to see their thoughts and feelings without judgment and to look at them simply as mental events that appear and vanish and that these thoughts are not aspects of themselves or and do not necessarily represent the reality. In this approach, it is assumed that individuals learn how not to be trapped by thought rumination patterns (Teasdale et al, 2002).

\section{References}

[1] Mahram, B. \& Saketi, P. 2008. The role of curriculum components in college students' self-control (Case study: Ferdowsi University of Mashhad). A collection of articles presented in the Fourth Seminar of students mental health, Shiraz University, 1-2 June, 9971000.

[2] Tangney J P. Baumeister R F. Boone A L. 2004. High self-control predicts good adjustment, less pathology, better grades, and interpersonal success.Journal of Personality, 72: 271-322. 
[3] Gottfredson M R. Hirschi T. 1990. A general theory of crime.1st Edition. Stanford ‘CA: Stanford University Press.

[4] Safari Dehkharqani, N. 2008. Comparing the effectiveness of Parkinson impulse control and self-control training on the reduction of the carelessness of adolescent girls in Tehran. Master's thesis in General Psychology, Faculty of Education and Psychology. Allameh Tabatabaei University.

[5] Ost LG. 2008 .Efficacy of the third wave of Behavioral therapies: A systematic review and meta-analysis. Behavior Research and Therapy, $49: 296-321$.

[6] Segal E .et al. 2003 .Module networks: identifying regulatory modules and their condition-specific regulators from gene expression data. Nat Genet 34:166-76.

[7] Gibson, R. \& Michelle M. 1994. Principles of counseling and guidance. Translated by Sanaee Zaker, B. et al. Tehran, Virastar Publications.

[8] De Ridder DT D. de Boer B J. Lugtig P. Bakker A B. \& van Hooft E A J. 2011. Not doing bad things is not equivalent to doing the right thing: Distinguishing between inhibitory and initiatory self-control. Personality and Individual Differences ،50: 1006-1011.

[9] Sarafraz, M., Qorbani, N. \& Javaheri, N. 2012. Self-Control: Unidimensional or Multidimensional Capacity? Distinction between the Inhibitory and Initiatory Facets among students of Tehran University. Research on mental health, 4: 69-75.

[10] Eyles C .Leydon GM .Hoffman CJ .Copson ER .Prescott P.Chorozoglou M .Lewith G. 2015 .Mindfulness for the self-management of fatigue, anxiety, and depression in women with metastatic breast cancer: a

[11] Yusainy C . Lawrence C .2015. Brief mindfulness induction could reduce aggression after depletion .Conscious Cognition ،33:34125.

[12] Wittmann M .Peter J. Gutina O. Otten S. Kohls N. Meissner K. 2014. Individual differences in self-attributed mindfulness levels are related to the experience of time and cognitive self-control. Personality and Individual Differences. 64: 41-45.

[13] Bowlin S L .Baer R A. 2012. Relationships between mindfulness, self-control, and psychological functioning .Personality and Individual Differences ، 52: 411-415.

[14] Friese M. Messner C. Schaffner Y. 2012 .Mindfulness meditation counteracts self-control depletion. Consciousness and Cognition, 21: $1016-1022$.

[15] Poorshahsavari, F. 2011. The effectiveness of mindfulness-based cognitive therapy to increase self-differentiation and affective selfregulation. Master's thesis of counseling, Faculty of Psychology and Educational Sciences. Payam-e-Nour University of Sirjan.

[16] Ahmadi, H. S. 2009. The effectiveness of problem solving training to increase purposefulness, positive affect and self-control among purposeless adolescents. Master's thesis in clinical psychology. Faculty of Psychology and Educational Sciences. Allameh Tabatabaei University.

[17] Teasdale, J. D., Moore, R. G., Hay Hurst, H., Pope, M., Williams, S., \& Segal, Z. V. 2002. Metacognitive awareness and prevention of relapse in depression: empirical evidence. Journal of Consulting and Clinical Psychology, 70:275-287. 